\title{
IDENTIDAD Y MOVIMIENTO ORGANIZAIIVO EN LA AMAZONÍA PERUANA
}

\author{
Alberto Chirif \\ Universidad Nacional Mayor de San Marcos - Perú
}

Resumen: En la presente contribución se analizan las categorías genéricas de "indígena" y "mestizo" con el objetivo de echar luz sobre cómo ellas juegan en el proceso de occidentalización de la sociedad envolvente llamada "peruana" y sobre la necesidad de que los sujetos de ambas categorías se aproximen en función de fortalecer el movimiento indígena en el Perú. Para ello se centra el análisis tanto sobre el "mundo andino" como sobre el "mundo amazónico" peruano, develando sus avances y contradicciones en la dinámica de un proceso organizativo permeado por la construcción y reconstrucción de la identidad.

Resumo: Na presente contribuição, se analisam as categorias genéricas de "indígena" e de "mestiço" com o objetivo de esclarecer como operam estas duas categorias no processo de ocidentalização que parte da sociedade envolvente chamada "peruana" e sobre a necessidade de que os atores de ambas as categorias se aproximem em função de fortalecer o movimento indígena no Peru. Por esse motivo, se concentra a análise tanto sobre o "mundo andino" quanto sobre o "mundo amazônico" peruanos, desvelando seus avanços e contradições na dinâmica de um processo organizativo permeado pela construção e pela reconstrução da realidade.

¿Quiénes son y quiénes no son indígenas en el Perú? ¿Se trata de una cuestión puramente subjetiva, es decir, librada a la voluntad individual de quienes se reconocen dentro de esa categoría genérica de 'indígenas', o es un asunto de carácter objetivo, que tiene que ver con la forma cómo las sociedades diferentes que han sido englobadas dentro de la estructura política administrativa del Estado realizan sus relaciones sociales y productivas? Por otro lado, nos podríamos preguntar, igualmente, quiénes son mestizos en el Perú y 
si esta categoría, tan genérica como la anterior, sirve de por sí para explicar la complejidad social, cultural y política del país. En otras palabras, ¿qué significa este mestizaje que, a decir de muchos, implica la occidentalización de los indígenas y cómo, verdaderamente, habría que definir el carácter occidental de la sociedad peruana.

Consideramos pertinente intentar una aproximación al tema por la importancia que tiene para la expansión y consolidación de un movimiento indígena como el del Perú que no se ha planteado el problema y, por lo mismo, ha limitado su accionar a aquellos sectores que, motu propio, han declarado su indigenidad, descuidando a aquéllos otros que, por diversas razones, no han dado el mismo paso. Con esta actitud, también ha restringido sus propias posibilidades de fortalecimiento.

\section{El mundo andino}

Intentaremos, primero, una aproximación al mundo andino a partir de una pregunta básica: ¿por qué en esta región, donde la población indígena es mayoritaria, no ha surgido un movimiento reivindicativo con una perspectiva indígena? A nuestro modo de ver, esto tiene que ver con dos factores: la manera cómo se han desarrollado allí las fuerzas productivas y la influencia que han tenido ideologías externas, tanto de sectores de la derecha como de la izquierda.

Hablar del primer factor nos lleva a referirnos, antes que nada, a la gruesa clasificación que se hace de la población andina en quechuas y aymaras. Si bien en el caso de estos últimos hay una coincidencia entre sociedad, cultura y lengua, entre los primeros no es así. Los ahora llamados quechuas fueron, antes de ser conquistados por los Incas, pueblos diversos con identidades y lenguas particulares. Además de tributos y servidumbres, a ellos se les impuso el quechua que, como toda lengua, no es más que un vehículo de comunicación. Pero los Incas no crearon una nueva identidad social. Como todo Estado, sus objetivos centrales apuntaban hacia la articulación política administrativa.

La facilidad con que los españoles llevaron a cabo la conquista del Imperio se explica por esta falta de identidad y solidaridad de pueblos que habían sido dominados por un Estado, que, por lo demás, tenía apenas más de un siglo de establecido. Aunque con alguna mayor resistencia, también los 
Aztecas cayeron rápidamente bajo dominio hispano por la misma razón. No obstante, no sucedió lo propio con pueblos como los Mapuche, quienes, a la llegada de los europeos, no estaban bajo el poder de ningún Estado. Ellos enfrentaron no sólo a las fuerzas de la Corona sino también, y hasta comienzos de este siglo, al propio ejército chileno.

Es así que la 'identidad quechua' resulta insuficiente como para promover un movimiento organizativo de la población indígena andina. Por tanto, sería necesario un trabajo de búsqueda que intente recuperar las identidades particulares, cosa que hasta hoy no se ha hecho de manera sistemática y políticamente orientada hacia la consolidación de organizaciones representativas.

Pero durante el dominio de la Corona y, luego, de la República, los cambios producidos en las sociedades andinas fueron mucho más brutales y desarticuladores que los realizados durante el periodo Inca. El trabajo en las minas y en otras servidumbres significó la esclavitud de los pobladores andinos, quienes dejaron de ser agricultores para pasar a ser simplemente mano de obra al servicio de intereses ajenos. La caída demográfica como consecuencia del maltrato y de las enfermedades introducidas, repercutió también directamente sobre la organización social.

El proceso de mestizaje se aceleró no sólo como consecuencia inevitable de un mayor contacto con 'los otros', sino también como una estrategia de sobrevivencia individual de muchos que vieron en el dejar de 'aparecer' como indígenas una posibilidad de acercamiento al poder o, por lo menos, de recibir un trato menos brutal a cambio de aliarse con el conquistador y de servir de intermediarios entre éste y el sector más explotado de sus propios pueblos.

Más tarde, leyes como la de Bolívar, quien, recién iniciada la República, estableció que los indígenas podían vender libremente sus tierras (con una mentalidad liberal que hoy encuentra nueva vigencia), llevaron a que muchos se desprendieran de ellas. Surgieron así los latifundios, que también se constituyeron por métodos abiertamente violentos al amparo de autoridades al servicio del poder.

El proceso general de minifundización de la propiedad rural repercutió sobre la organización de las comunidades, y el trabajo se volvió cada vez más individual. La proletarización creciente, sobre todo por el trabajo en las minas, la individualización de la propiedad fundiaria, el crecimiento del comercio y la manera cómo muchos indígenas se fueron implicando en éste como medianos 
empresarios, y el esfuerzo por apartarse de su propio pasado y de acercarse al mundo ‘del otro' para así poder sobrevivir con ciertas ventajas, constituyen las características de un contexto muy poco propicio para el nacimiento de un movimiento reivindicativo indígena en la región. A éstas habría que agregarle una más, que es el papel jugado por las distintas ideologías políticas.

Es importante traer a la reflexión la manera cómo algunos de los más conspicuos representantes de la derecha han encarado el asunto. Para José de la Riva Agüero, el más notable de los historiadores de la aristocracia limeña, la conquista produjo el mestizaje de la población. A partir de entonces, para él ya no es dable hablar de indígenas y no indígenas sino de peruanos mestizos. Entiende por mestizaje no más de lo que puede entender un botánico o un zoólogo respecto a un cruce de especies: sobre una matriz (útero) indígena, España injertó la savia de la civilización: lengua, ciencia, religión y, por supuesto, sangre. Es decir, ve el asunto como la fecundación de la barbarie por la civilización y de la irracionalidad por la razón. Su posición lo lleva a eludir, de una manera cómoda, las contradicciones, choques e injusticias producidas por la conquista y a abogar, sin hacerlo explícito, porque las cosas continuasen como estaban.

La izquierda, en cambio, sí reaccionó contra la explotación del indígena. A los indigenistas de las primeras décadas de este siglo, quienes circunscribieron su acción, sobre todo, a denuncias hechas ante el Gobierno y el Congreso, les seguirían partidos políticos con planteamiento prácticos para encarar el problema de los indígenas como clase explotada. Es así que ellos propiciaron la formación de sindicatos y organizaciones agrarias para encarar los problemas desde una perspectiva clasista: acceso a la tierra, mejoras en las condiciones laborales, de comercialización, educación, salud y otras. Pero las reivindicaciones de los indígenas andinos como miembros de pueblos distintos y la integración de los problemas mencionados dentro de una concepción que los unificara, pasaron desapercibidas para la izquierda.

Un hecho significativo se produjo en 1969 cuando el General Juan Velasco Alvarado, quien había encabezado un golpe de Estado con características sui generis que lo había llevado al poder un año antes, promulgó la Ley de Reforma Agraria. Esta Ley cambió el antiguo concepto de indígena por el de campesino, porque el Gobierno consideró que ése era peyorativo. La medida era producto de una confusión conceptual, ya que consideraba los 
términos ‘indio' e 'indígena' como sinónimos, cuando en realidad el primero era consecuencia del error histórico de Colón, mientras que el segundo sirve para designar a la población originaria o nativa de un lugar. Sea como fuere, este cambio de términos ha sido importante dentro de la historia reciente y, en gran medida, ha sido incluso agradecido por comunidades andinas y costeñas antes calificadas de indígenas, que vieron así apuntalada su estrategia de sobrevivencia frente al racismo imperante. Es en ese momento histórico que también se acuña el término nativo, esta vez para referirse a los amazónicos como entidad distinta a la de las otras dos regiones del país.

Como consecuencia de la resonancia generada por organizaciones indígenas en diversas partes del mundo, apareció en el Perú, luego de la reunión de Barbados II (1977), el Movimiento Indígena Peruano (MIP). Montado por intelectuales, entre ellos, un antropólogo de evidente ascendencia indígena que regresaba al país después de vivir durante años en Europa, el MIP no partió ni se orientó hacia las bases sino que se quedó en su círculo de origen, produciendo apenas un debate teórico de escasa significación. Poco más tarde, al enfrentarse sus gestores y aparecer en escena el Consejo Indio Sudamericano (CISA), dicho antropólogo se integraría a éste que, por su parte, tampoco lograría arraigo popular en los Andes peruanos y muy limitado en la Amazonía.

Pero lo indígena no ha desaparecido en los Andes peruanos. Muchas comunidades conservan fuertemente sus características particulares, especialmente aquéllas más apartadas de los circuitos comerciales y de las influencias ideológicas partidarias. El hecho que no se declaren indígenas significa poco en términos de su propia dinámica. Sin embargo, sí es importante cuando se trata de formar organizaciones representativas, ya que entonces 'indígena' funciona como una categoría política que sirve para aglutinar pueblos originarios distintos pero con problemas similares debidos a su forma de inserción en la sociedad nacional, los cuales necesitan aunar fuerzas para darle mayor impulso a sus planteamientos. Esta necesidad de búsqueda, de alianzas que fortalezcan a las partes respetando sus diferencias, está también presente en movimientos como el de la negritud. Volviendo al tema, es necesario recordar que hasta ahora ningún pueblo se ha declarado como indígena sin antes haberse afirmado en su particularidad: Asháninca, Aguaruna, Chiquitano, Shuar u otra. De ahí que pensamos que mientras esto no suceda no habrá posibilidad de impulsar organizaciones indígenas en los Andes peruanos. 
Tampoco podemos decir que lo indígena haya desaparecido en las comunidades andinas más vinculadas al mercado y más influidas por la ideología dominante. La vigencia de la música y las fiestas (elementos importantes para la recreación cultural), y de relaciones sociales regidas por la reciprocidad dan prueba de ello.

La presencia del mundo andino indígena se ha extendido incluso hasta Lima, es decir, hasta el centro mismo del poder político y económico, en un proceso similar al que se observa en muchas de las antiguas metrópolis, hoy fuertemente influidas por gente de sus ex colonias.

\section{La Amazonía}

En la Amazonía la situación es distinta, aunque a veces existen situaciones similares a las antes mencionadas. Si bien los pueblos indígenas de la región, en un primer momento, cayeron bajo el dominio de las reducciones misionales, luego se resistieron a éste internándose en el bosque y destruyendo los poblados coloniales. El poco interés de la región para el español colonizador y las limitaciones que ella presentaba para el desarrollo de empresas productivas estables, favoreció a esos pueblos al reservarles un cierto aislamiento que les ha permitido mantener mayor cohesión.

Sin embargo, hubo también casos parecidos a los señalados para los Andes. Por ejemplo, los Cocamilla y, sobre todo, los Cocama. Con sistemas de organización social, económica y política más complejos y dependientes de la vida en las riberas de los grandes ríos amazónicos, pues era allí donde ellos obtenían sus excedentes, sufrieron una profunda desestructuración a causa de la actividad misional y de las correrías esclavistas desatadas por los portugueses que venían del este. Durante la República, muy temprano, al establecerse la navegación fluvial por esos ríos, el impacto sobre ellos continuó al punto que no sólo perdieron su lengua sino que también optaron por esa estrategia de sobrevivencia a la que hemos aludido en el caso de los andinos, de negar su propio origen para así parecer menos diferentes al dominador.

Si para los Cocama el impacto fue profundo y además sostenido en el tiempo, para otros, en cambio, a pesar de haber tenido características mucho más dramáticas, no tuvo la misma duración ni ejerció la misma influencia ideológica. Es el caso de los Yanesha y los Asháninca, quienes, a fines del 
siglo pasado, vieron cómo sus territorios eran invadidos, primero, por colonos europeos y, más tarde, por oleadas de colonos andinos; y, en especial, de los Bora, Huitoto y Ocaina, quienes, en la misma época, fueron invadidos por bandas armadas por los caucheros para esclavizarlos y someterlos a la recolección del jebe.

El choque de estos últimos pueblos con los colonizadores, siendo muy impactante, no consiguió descaracterizarlos por completo. De ahí que reemprendieran la búsqueda de una vía propia para reafirmar sus derechos como pueblos originarios. Fueron los Yanesha y Asháninca quienes impulsaron las primeras organizaciones indígenas en el Perú. Los Bora, Huitoto y Ocaina no tardarían mucho en hacer lo mismo.

Por su parte, los Cocama constituyen el principal componente de esa cultura llamada ribereña a la cual se han sumado, más en términos individuales que colectivos, representantes de otros pueblos que han sufrido también procesos de descaracterización social: Chamicuro, Jebero, Yagua, Ticuna, Bora y Huitoto. Estos, junto con inmigrantes llegados de San Martín en la época del caucho, conforman, después de la crisis a consecuencia de la caída del precio del jebe, comunidades libres, hoy conocidas como 'ribereñas'. No se trata de colonos, de gente ajena a la región, sino de población amazónica que posee conocimientos, tecnologías y formas de organización social de indudable origen indígena. Esta realidad es la que ha permitido que, en los últimos años, en Loreto, que es donde mayoritariamente se encuentra ese sector social, haya aparecido un fenómeno inédito: la reindigenización de los ribereños.

Los primeros en pasar por este tránsito fueron los Cocamilla asentados en el curso bajo del Huallaga. En la segunda mitad de los 70, constituyeron la Federación de Comunidades Cocamillas (FEDECOCA). Si bien es cierto que hubo la intervención de un agente externo en el proceso, en este caso, un antropólogo estadounidense que, en el curso de su investigación, propició la organización política de este Pueblo, este hecho, de por sí, es insuficiente para explicar el por qué la gente explicitó su identidad al dar nacimiento a esa organización. En otras palabras, si la identidad de los Cocamilla no hubiese estado subyacente, la labor de cualquier agente externo hubiese sido infructuosa. Los elementos vigentes de su propia cultura que permitieron esto fueron: el uso de apellidos cocamillas, que seguramente no sólo identifican familias sino clanes 
u otra forma de organización tradicional, los matrimonios entre gente del propio Pueblo, el sistema de reciprocidad como base de las relaciones sociales, el uso de tecnologías autóctonas y la actualidad de sus sistemas de creencias.

La emergencia, desde inicios de los 70, del movimiento indígena amazónico en el país y su rápido crecimiento e influencia a nivel regional y nacional, sirvió también de estímulo para que pueblos como los Cocama y los Cocamilla se reafirmaran como indígenas.

De una u otra manera, estas dos razones (vigencia de la propia tradición e influencia de agentes externos, sean éstos o no indígenas), explican también los procesos posteriores de reindigenización de cocamas, jeberos e iquitos y de gente de otros pueblos que, luego de vivir durante décadas inmersos en contextos de mestizaje, han seguido el camino de la reafirmación propia. Está también el caso de algunas comunidades huitotas del río Nanay, quienes, hace apenas unos dos años y a pesar de la oposición de funcionarios del Ministerio de Agricultura y del campesinado vecino, han revindicado su carácter indígena y constituido una federación que las represente.

\section{La organización indígena en la Amazonía}

\section{Los inicios del movimiento}

En la Amazonía peruana, al igual que en cualquier parte del mundo, la primera motivación de los indígenas para organizarse ha sido la lucha por la tierra. Decimos tierra y no territorio porque, en el Perú, el desarrollo teórico de este concepto y su conversión en bandera política del movimiento ha sido un fenómeno posterior que ha tenido que ver, por un lado, con su propio avance y, por otro, con la influencia recibida de organizaciones indígenas más antiguas de otras latitudes. También, porque las primeras organizaciones que surgieron respondían a los intereses de pueblos que habían perdido sus territorios mucho tiempo atrás y, por tanto, sólo podían aspirar en ese momento a la defensa de lo que les quedaba a los asentamientos locales, que habían sido oficialmente bautizados con el nombre de comunidades, y, en el mejor de los casos, a la restitución de algunas porciones adicionales.

En efecto, los primeros esfuerzos organizativos en la Amazonía peruana fueron realizados por los Yanesha (Amuesha) y los Asháninca. Mientras que los 
primeros habían comenzado a experimentar la invasión de su territorio en 1840 (Pozuzo, Oxapampa y, más tarde, Villa Rica), cuando el Estado, a través de leyes promocionales, estableció en él a colonos alemanes y tiroleses; los segundos, desde fines de ese siglo, vieron cómo parte importante de su territorio (en particular, la cuenca del Perené y, en parte, la del Pichis) pasaba a dominio de una empresa británica que recibía las tierras como compensación de una deuda contraída por el gobierno, a causa de la guerra con Chile. Dada la proximidad de estos dos pueblos, también los Yanesha serían afectados por esta empresa que, por su parte, comenzaría a sufrir, en 1940, los estragos de la invasión de sus propiedades por colonos provenientes de los Andes vecinos. Así, hacia mediados de este siglo, la situación para ambos era especialmente complicada y dramática.

Tal como lo relata un bien documentado artículo de un comunero asháninca (Casanto, 1986), una comisión de la Cámara de Diputados, en 1959, ordenó el libre tránsito por las propiedades de la empresa británica que, hasta ese momento, se mantenían como un enclave feudal, con fronteras cerradas y obligatoriedad de presentar salvoconductos para quienes quisieran sobrepasarlas. Al mismo tiempo, dispuso también que se entregaran, en la margen derecha del río Perené, 400,000 hectáreas para los colonos que se habían ido asentado de manera espontánea.

Al llegar esta noticia a oídos de los ashánincas, parte de los cuales se habían trasladado hacia zonas libres de la influencia británica, ellos se empezaron a organizarse para reclamar sus propios derechos. A mediados de 1959, en la comunidad de Tsotani (río Perené), se reunieron 120 indígenas para constituir una organización representativa para la defensa de las tierras, a la que llamaron “Asociación de Nativos Campas [Asháninca] del Perené”, acordando también constituir una alianza con los colonizadores, cuyo objetivo era lograr el respeto de las tierras de ambas partes.

En posteriores asambleas de la Asociación, las comunidades, junto con los colonos, acordaron la construcción de una serie de campos de aterrizaje y escuelas, y también solicitar 'reservas' de tierra para las comunidades. Estas últimas habían sido normadas por un decreto supremo dado por el gobierno en 1957, a través del cual, al parecer, el Estado respondía a los compromisos que había asumido al ratificar el Convenio No 107 de la OIT.

Sin embargo, la alianza se rompería poco tiempo después a consecuencia de fricciones e intereses contrapuestos entre las partes. Al incrementarse los 
flujos migratorios andinos a partir de 1963, se producirían enfrentamientos entre ashánincas y colonos.

En 1968 llega al poder el General Juan Velasco Alvarado encabezando un gobierno de corte nacionalista. Dos años más tarde, las comunidades ashánincas del Perené y del Pichis comenzarían a reunirse en asambleas periódicas. Allí se originaron las organizaciones indígenas de esas cuencas, que se conocieron en un momento con el nombre de "Congresos Nativos Campa”. Constituidos éstos, los indígenas comenzaron a exigir una ley especial para el tratamiento de sus derechos, que finalmente sería promulgada en 1974. Esta fue la primera ley específica para pueblos indígenas amazónicos dada durante la República.

Desde entonces, en esa zona se sucederían una serie de experiencias organizativas de diversos signo: en 1975, el Comité de Comercialización Agropecuaria de Productos Ashánincas Campas de Marankiaria (CCAPACAM); en 1976, el Comité de Comercialización de Productos Agropecuarios de la Comunidad de Kivinaki (CCOPACK); ese mismo año, la Federación de Comunidades Nativas del Perené (FECONAPE); en 1977, la Central de Comunidades Nativas de Producción y Comercialización Agropecuaria del Perené (CCONAPCAPE). Finalmente, esta última, con el objeto de darle a la organización un carácter político representativo y no sólo empresarial, se constituiría, en 1978, en la Central de Comunidades Nativas de la Selva Central (CECONSEC), que funciona hasta hoy y es una de las bases que fundaron AIDESEP. Su ámbito inicial, que incluía los valles del Pichis, Palcazu y Perené, quedaría luego circunscrito sólo a este último y la zona de Satipo, creándose en los otros nuevas organizaciones.

Las comunidades de las vecinas zonas de Oxapampa, Villa Rica y Palcazu, habitadas por los Yanesha, como fruto de un trabajo de animación iniciado 3 años antes por un antropólogo estadounidense, realizaron, en 1979, la primera asamblea general de representantes de este Pueblo, en la que se constituyó el Congreso Amuesha. Esta organización pionera tuvo también como tema central la defensa de las tierras. En ese momento buscaba garantizar a las comunidades las tierras que ellas habían podido mantener bajo su dominio a lo largo de un proceso de colonización que se había iniciado hacía más de un siglo y reclamar áreas para ampliar su tenencia. El Congreso tuvo vigencia hasta 1981, cuando una serie de controversias 
internas, motivadas por la politización partidaria de su dirigencia, lo llevaron a disolverse y a dar paso a la Federación de Comunidades Yanesha (FECONAYA), hasta hoy existente. Dichas pugnas y las luchas personales entre esos dirigentes y los de la naciente AIDESEP, darían como resultado que la Federación nunca se integrara a esta organización nacional, a pesar de haber participado activamente en las reuniones preparatorias de su lanzamiento. La FECONAYA es hoy una de las bases más sólidas de una segunda organización indígena amazónica: la Confederación de Nacionalidades de la Amazonia Peruana (CONAP).

Mientras tanto, en el Ucayali, a inicios de los años 70, se producían también una serie de intentos organizativos, unos de carácter representativo, otros, más bien empresarial. La Federación de Comunidades Shipibas (FECONASH) sería, poco tiempo después, suplantada por la Organización de Desarrollo Shipibo (ORDESH), que si bien aún subsiste, tiene poca vida real. Más tarde surgiría la federación de Comunidades Nativas del Ucayali (FECONAU), también formante de AIDESEP. En su camino, parte de sus bases iniciales se irían reagrupando en nuevas organizaciones: los Cashibo-Cacataibo crearían la Federación de Comunidades Nativas Cashibo (FECONACA); los shipibos de la provincia de Ucayali darían origen a la Federación de Comunidades del Bajo Ucayali (FECOMBU); y algunas comunidades de la parte alta formarían la Organización de Desarrollo de Comunidades Nativas del Distrito de Tahuanía (ORDECONADIT). El planteamiento central de la organización del Ucayali fue no tanto la tierra, puesto que la cuenca no era objeto de planes masivos de colonización, sino la defensa de los derechos de las comunidades sobre los 'barreales' (terrenos aluviales) y lagunas; adicionalmente, su finalidad era también obtener mejores ingresos del turismo que diversas empresas privadas realizaban en sus caseríos y de la comercialización de artesanías.

En la Amazonia norte, por su parte, se desarrollaban dos procesos de organización, uno con los Aguaruna y otro con los Cocamilla. El primero comenzó a gestarse en 1972, cuando la Misión Jesuita establecida en el Alto Marañón propició la venida de un grupo de profesionales españoles para apoyar actividades de desarrollo en las comunidades. Antes de transcurrido un año, éstos entraron en contradicciones con los sacerdotes y se independizaron. Este grupo, organizado bajo el nombre de "Desarrollo del 
Alto Marañón” (DAM), alentó la organización de las comunidades por cuencas. Se formaron así cinco centrales en el Alto Marañón y sus afluentes más importantes. Sobre la base de ellas fue que se creó, en 1975, el Consejo Aguaruna Huambisa (CAH), cuyos principales objetivos fueron la defensa de las tierras y recursos forestales de las comunidades (desde 1967 esa parte de la cuenca estaba sometida a planes de colonización militar), y la autonomía de la conducción política de la organización. El Consejo atraviesa hoy, por una etapa de crisis, dado que los Huambisa han tomado la decisión de conformar una federación independiente.

Por otro lado, las comunidades del bajo Huallaga, también con el apoyo motivador de un antropólogo estadounidense, conformaron, en 1977, la Federación de Comunidades Cocamillas (FEDECOCA), teniendo como objetivo central la defensa de los lagos.

Al constituirse formalmente AIDESEP en 1985, como parte de un proceso que trataremos más adelante, son cuatro las organizaciones que aparecen firmando las actas: CECONSEC, FECONAU, CAH y FEDECOCA.

\section{La fundación de AIDESEP}

En la segunda mitad de la década de los 70 existían ya varias organizaciones indígenas constituidas en la cuenca amazónica peruana. Al mismo tiempo, habían diversos profesionales quienes, desde distintas ubicaciones (Estado, ONGs, individualmente), trabajaban temas vinculados con la región y, particularmente, con los pueblos indígenas. Finalmente, grupos activos de estudiantes de dos universidades interesados en la problemática, realizaban trabajos de campo y asumían compromisos políticos con los indígenas. Sin embargo, el conocimiento entre la gente que integraba cada uno de los tres conjuntos señalados era escaso. Con la finalidad de superar este aislamiento fue que, en 1977, se realizó una primera reunión que congregó a la mayor parte de los profesionales y estudiantes. El entusiasmo generado durante ese primer encuentro llevó al grupo a tomar como acuerdo la repetición periódica de las reuniones, con los objetivos de continuar con la reflexión y análisis de los problemas, de unificar criterios básicos y de promover trabajos conjuntos para la defensa de los derechos indígenas. Más tarde, el grupo adoptaría el nombre de "Copal, Solidaridad con los pueblos nativos". 
A partir de la segunda reunión comenzaron a asistir líderes de las nacientes organizaciones de bases, cuya participación fue creciendo en las subsiguientes.

Eran los años finales de una larga etapa de un gobierno militar que, en sus inicios, había dado algunas medidas favorables al movimiento popular. Para los pueblos indígenas, en concreto, una ley que por primera vez les reconocía sus derechos sobre la tierra. No obstante, el momento era de crisis: desgaste del poder y cambios evidentes en la orientación política del gobierno, donde había ganado terreno un sector que buscaba manipular al movimiento popular.

Ante la crisis, los militares aceptaron traspasar el gobierno a los civiles a condición que se promulgase una nueva Constitución, tarea que quedó en manos de una Asamblea Constituyente elegida por voto popular. Aunque los partidos de izquierda lograron aproximadamente un 25\% de la representación en dicha Asamblea, ni éstos ni menos los de la derecha se mostraron interesados en los derechos de los indígenas. El panorama era preocupante, ya que se preveía (como en efecto sucedió) que el próximo gobierno estaría encabezado por Fernando Belaúnde Terry, quien en su primer mandato había ya alentado la masiva colonización de la Amazonía, proceso que tuvo como consecuencia el despojo a las comunidades de sus tierras y la extensiva deforestación en diversos valles.

Esta coyuntura era parte central de los análisis de los integrantes de Copal y de sus campañas destinadas a frenar el impacto sobre los indígenas de las políticas que se veían venir.

A comienzos de los años 80, durante el proceso de transferencia del poder a los civiles, los líderes indígenas expresaron su voluntad de continuar con las reuniones de coordinación pero solos, es decir, sin la presencia de no indígenas. Aunque sin hacerla explícita, la razón principal para ellos era que solos podrían desarrollar un diálogo más horizontal que les permitiría expresarse mejor, y a su ritmo, sobre los problemas y medidas a adoptar para solucionarlos. De esa ruptura (tema que retomaremos más adelanté cuando nos refiramos a la aparición de CONAP), producida en un ambiente de conflictos que no es del caso detallar, es que nace la Asociación Interétnica de Desarrollo de la Amazonía Peruana (AIDESEP).

La naciente organización establece también distancias con los partidos políticos y movimientos sociales liderados por éstos, al constatar que su 
preocupación mayor era la de captar nuevos adeptos y ensanchar sus bases, más que el incorporar sus propuestas específicas dentro de sus programas. Se produce un claro reclamo de autonomía por parte del movimiento indígena para tomar en sus manos la conducción de su propio proceso político. Algo similar ocurría con las organizaciones representativas de los otros países amazónicos, cuya unión daría como resultado, en la segunda mitad de los años 80, el nacimiento de la Coordinadora de Organizaciones Indígenas de la Cuenca Amazónica (COICA).

\section{Organización}

Aunque funcionaba como organización desde inicios de los 80, es recién en 1985 que AIDESEP se constituye jurídicamente y asume la gestión y administración de una serie de proyectos. Dado que la legislación peruana no contemplaba (ni lo hace hasta hoy) el reconocimiento legal de federaciones ni de confederaciones, la organización decidió, en 1985, conformarse como asociación civil sin fines de lucro, vale decir, como ONG (la misma alternativa ha sido adoptada por las federaciones que la integran). De esta manera le sería posible ejercer sus funciones de manera autónoma: comprar, vender contratar, otorgar poderes y, en fin, desarrollar las atribuciones jurídicas amplias que la ley contempla para este tipo de personas jurídicas.

Las federaciones que integran AIDESEP han aumentado rápidamente. De cuatro que firmaron su escritura de constitución, hoy son alrededor de 40 . Cuando se crea, el país era aún más centralizado que hoy, tanto a nivel de la administración pública como de las comunicaciones: todo confluía en la capital de la República. El escaso número de federaciones que le dieron origen (muy alejadas entre sí) y el centralismo, determinaron que se eligiera a Lima como la sede del movimiento.

En 1988, con la promulgación de la ley de regionalización, este panorama empezó a cambiar. Por la misma época se establecieron nuevas rutas aéreas y se construyeron nuevas carreteras que mejoraron la interconexión regional. Fue entonces cuando la asamblea nacional resolvió también iniciar la descentralización de AIDESEP, acordando la creación de oficinas regionales (OR) en Iquitos, Pucallpa, San Lorenzo y Selva Central (La Merced o Satipo). Salvo esta última, por razones financieras pero también por temor a la subversión, 
todas las demás han sido creadas y tienen, en mayor o menor grado, autonomía administrativa. A pesar de que las OR asumieron muchas de las funciones que antes se realizaban desde Lima, la descentralización no llegó a ser una medida suficientemente coherente, como veremos más adelante, y creemos que ésta es una de las razones que explica la crisis institucional posterior.

La directiva nacional se elige cada 3 años, aunque inicialmente los periodos eran de dos, tal como en realidad sigue figurando en los estatutos que no han sido modificados. El mantenimiento de estatutos que en la actualidad han devenido en obsoletos por el avance experimentado por la institución, por cierto que no es causa de la crisis pero sí una expresión de ésta, en tanto que muchas de las normas escritas hoy no se pueden cumplir porque la realidad ha cambiado.

El papel de las OR no ha sido reglamentado. No siempre sus dirigentes son elegidos, ya que a veces son nombrados por la dirigencia nacional, y sus funciones y atribuciones no están debidamente especificadas.

\section{Programas}

El funcionamiento de AIDESEP gira sobre la base de cinco programas, que someramente describimos a continuación:

Defensa - Incluye la cuestión territorial, tanto en lo que concierne a proyectos de demarcación como a cursos de capacitación legal sobre derechos de los pueblos indígenas. Dentro de este Programa funciona el proyecto de titulación del medio y alto Ucayali que, en su primera etapa, ha cumplido un rol fundamental en la organización, reconocimiento y defensa territorial de comunidades que se encontraban sometidas a la esclavitud por patrones madereros y ganaderos (ver AIDESEP, 1991a, 1991b, 1991c).

Educación - Tiene dos subprogramas: uno de becas para que jóvenes indígenas seleccionados por sus bases puedan seguir estudios superiores en universidades e institutos, con el compromiso de trabajar con sus federaciones luego que se gradúen; y otro de formación y profesionalización de maestros bilingües dentro de una perspectiva intercultural, en convenio con el Ministerio de Educación. La metodología de este último ha sido tomada por la Comunidad Europea como modelo para apoyar un programa educativo a nivel nacional en el Perú. 
Salud - Intenta el diseño de estrategias específicas para el tratamiento del tema en los pueblos indígenas y también la puesta en marcha de servicios comunitarios de salud.

Economía - Comprende la capacitación y asesoría a iniciativas regionales en los campos de la producción y comercialización. Tiene un subprograma, que es Huerto Integral Familiar Comunal (HIFCO). Sin embargo, éste no ha llegado a producir los resultados esperados de generar alternativas económicas para las comunidades.

Difusión - Se refiere especialmente a la edición de la revista Voz Indígena, con noticias, comentarios y análisis de la problemática de las comunidades.

\section{CONAP, su origen y la controversia con AIDESEP}

El nacimiento de AIDESEP, como ya antes mencionamos, fue traumático en tanto implicó un rompimiento entre los líderes de las nacientes organizaciones y los profesionales, independientes o asociados en instituciones, que los venían apoyando. El espacio de las ONGs sufrió un recorte, sobre todo en lo que respecta a su, hasta entonces, calidad de intermediarias exclusivas de los pueblos indígenas frente al Estado y a las agencias de cooperación. Al crecer rápidamente la organización, muchas federaciones afiliadas también se negaron a trabajar con las ONGs. Por otro lado, varias de esas agencias condicionaron la aprobación de proyectos de las instituciones de apoyo a la previa coordinación de éstas con AIDESEP, cosa que, por cierto, ninguna de las dos partes quería hacer.

Lejos de intentar una aproximación, esas instituciones declararon su hostilidad contra AIDESEP y buscaron desacreditarla alegando que no era una organización representativa sino una ONG cualquiera y, además, de carácter desarrollista. Aprovechando algunos vacíos y también resentimientos de ciertos líderes indígenas contra dirigentes de AIDESEP, algunos centros de apoyo impulsaron la formación de una organización paralela. Fue así que, en mayo de1987, se realizó en Lima la asamblea de constitución de la Confederación de Nacionalidades Indígenas de la Amazonía Peruana (CONAP).

El discurso de los centros de apoyo fue asumido por la dirigencia de CONAP: la organización debe cumplir un rol representativo y no asumir 
programas (como lo hacía AIDESEP, de allí la acusación de desarrollista), que tienen que seguir estando en manos de las ONGs. Como la legislación peruana no contempla el reconocimiento de federaciones ni de confederaciones, CONAP, luego de 9 años de existencia, no cuenta con personería jurídica. Por esta razón ha dependido, financiera y administrativamente, de dichos centros. Por ejemplo, sus dirigentes figuraban en las planillas de sueldos de uno de ellos.

Dos de los principales planteamientos que caracterizan tanto a AIDESEP como al movimiento indígena mundial son las reivindicaciones territoriales y la lucha por la autodeterminación. En relación a lo primero, las oposiciones de CONAP mientras estuvo dominada por los centros que la impulsaron ha sido total, alegando que los indígenas no podían pretender acaparar las tierras de la región (cosa que AIDESEP tampoco intentó). Cuestiones más detalladas al respecto pueden verse en un trabajo nuestro (Chirif, 1991).

En relación a la autodeterminación, la posición primera de CONAP era aun más sorprendente. Citamos textualmente la posición de CONAP, hecha pública en un artículo titulado "Deslinde con AIDESEP”, publicado en su boletín:

[...] como nativos somos un sector explotado más en la sociedad, igual que los obreros, campesinos, capas medias y otros sectores sociales. Tenemos nuestras diferencias, pero no por eso podemos hablar de 'autodeterminación' o 'proyecto indígena: independiente del proyecto histórico popular. [...] Si AIDESEP quiere formar una serie de mini-estados 'autodeterminados' y completamente independientes del resto del Perú que lo diga francamente. Esto es separatismo y en las actuales condiciones es un sueño, un 'ideal' que le hace el juego a quienes quieren ver eternamente divididos a los sectores explotados. Los de AIDESEP se avergüenzan de plantear abiertamente sus tesis separatistas porque saben que nadie los seguiría, al margen de que en el plano jurídico están totalmente perdidos. Sino, imaginemos por un momento a grupos asháninkas al margen del Estado peruano, sin que las leyes ni la Constitución tengan vigencia en sus territorios. En esas condiciones, ¿habrán resuelto todos sus problemas? (CONAP, 1990).

El lenguaje utilizado en la cita precedente es suficientemente ilustrativo para medir el nivel de injerencia externa en CONAP y para evaluar su grado 
de alejamiento respecto a los postulados principales del movimiento indígena internacional.

En fecha reciente, el dominio de los centros sobre CONAP se ha debilitado, y los actuales líderes de esta organización parecen estar dispuestos a iniciar un acercamiento con AIDESEP. Consultando algunos documentos del año 1995 de esa confederación, describiremos su actual organización y campos de trabajo.

\section{Organización}

Según se describe en uno de esos documentos ("Presentación institucional”, que aunque no está fechado sabemos que corresponde a 1995, ya que lo firma el presidente que asumió el cargo ese año), el organigrama de CONAP es el siguiente:

- Asamblea General de Asociados o Congreso Nacional.

- Consejo Directivo.

- Organismos consultivos (asesoría).

- Sedes regionales: norte (Alto Marañón), oriente (Iquitos), oriente nor centro (Pucallpa), selva central (Satipo) y selva sur (Urubamba).

Como bases regionales declara 23, algunas de las cuales mantienen una ambigua relación ya que, a su vez, están también afiliadas a AIDESEP. Es el caso de FEDECOCA, PEPYBABAN, ORKIWAN, FECONAU Y FENAMAD. En el caso de dos que aparecen en la lista de CONAP, su inclusión es abiertamente arbitraria, ya que trabajan de manera estrecha con AIDESEP. Son FECONAFROPU y FECONARINA. Respecto a esta última, la desinformación de CONAP es evidente, ya que la define como Federación de Comunidades Nativas del Río Napo y Afluentes, cuando en realidad se trata de la federación del río Nanay.

Su Consejo Directivo está integrado por 12 personas, cuyos cargos son por un periodo de 4 años. El quorum para las reuniones es de tres personas: presidente, vice presidente y secretario de economía o algún otro miembro. 
Campos de trabajo

CONAP señala como sus “áreas básicas” las siguientes:

- Defensa y consolidación organizativa.

- Formación de cuadros dirigenciales.

- Derechos Humanos.

- Promoción de la mujer amazónica.

- Protección ambiental y desarrollo sustentable de la Amazonía.

- Fortalecimiento de la capacidad productiva de las comunidades.

- Difusión y comunicación.

Como el documento no explica en qué consiste cada una de estas áreas y tampoco tenemos noticias concretas sobre cuál ha sido el desarrollo de ellas, no nos es posible evaluar el funcionamiento de CONAP. Llama sí la atención que entre ellas no aparezca ninguna que aluda al territorio, cuestión apenas mencionada dentro de lo que la organización califica como "proyectos", donde se refiere a la "defensa del gas de Camisea". A pesar de esto, su posición sobre el tema parece haber cambiado en relación a sus primeras épocas. En un documento producido por el anterior Consejo Directivo ("Discurso presentado por CONAP ante el acto inaugural del Decenio Internacional de las Poblaciones Indígenas del Mundo”, Lima, 9 de diciembre, 1994), entre otras demandas, señalan la siguiente:

Reconocimiento, Titulación y Ampliación de nuestros Territorios, estableciendo Reservas Comunales y administración de los Parques Nacionales y Bosques de Protección por las propias Comunidades Nativas.

\section{AIDESEP, logros y crisis}

Logros

a) Levantar, por primera vez en el país, la bandera de reivindicaciones indígenas, constituye sin duda el primer y principal logro de la organización. 
Si bien antes se había planteado el tema, éste siempre había estado intermediado por agentes indigenistas pero nunca liderado directamente por los propios interesados.

b) Crear, muy rápidamente, un espacio propio convirtiéndose en interlocutor del movimiento ante el Estado, las agencias de cooperación y, en general, la sociedad civil.

c) Constituirse en tribuna de reflexión y propuestas del movimiento indígena nacional y vincularse al movimiento indígena internacional.

d) Fortalecer las demandas indígenas de las organizaciones regionales a través de asesoría, capacitación y presiones ejercidas tanto a nivel nacional como internacional.

e) Desarrollar propuestas teóricas y conseguir avances prácticos respecto al territorio indígena, vinculando a éste con la problemática medioambiental y social. En casos como el Alto Ucayali, además, la consolidación territorial marchó paralela a la organización de comunidades que fueron, en ese momento, rescatadas de la esclavitud a la que se encontraban sometidas por parte de patrones maderos y ganaderos. El hecho de que hoy el alcalde de Atalaya, el principal centro de poder regional de esos patrones; sea un indígena, es una buena prueba de cuánto ha podido avanzar en movimiento desde 1988, año en que AIDESEP inició su trabajo en la zona (AIDESEP, 1991a, 1991b, 1991c).

f) Desarrollar, también por primera vez en el país, una propuesta educativa basada no sólo en el bilingüismo, cosa que desde hace más 40 años se viene haciendo en el país, sino en una metodología de carácter intercultural, que partiendo de los conocimientos de los propios pueblos indígenas se acerca, libre de prejuicios; hacia los conocimientos elaborados por la ciencia occidental. Dentro de esta perspectiva, por primera vez las lenguas indígenas no son más tomadas como vehículos de tránsito hacia la castellanización ni como herramientas que se utilizan para perpetuar la ideología dominante, sino que son consideradas como instrumentos creados por una sociedad para conceptualizar e interpretar su realidad, que tienen plena posibilidad para seguir desarrollándose en el momento actual, a fin de incorporar nuevos conceptos técnicos y científicos. 


\section{Crisis}

Intentaremos señalar las causas de la actual crisis de AIDESEP.

a) Si bien su rápido crecimiento sirvió para darle presencia nacional e internacional al movimiento, por otro lado, éste se produjo a expensas de una cierta debilidad de sus cimientos. Bajo el influjo y entusiasmo generado por la organización, se fueron creando una serie de federaciones, no todas, sin embargo, habían realizado su propio proceso de maduración interno. Así, muchas no han visto a AIDESEP como un movimiento político que debe ser construido también con su aporte reflexivo, sino solamente como un sustituto del Estado o de centros de apoyo a la cual hay que pedirle servicios, infraestructura, créditos, donaciones y otras cosas por el estilo. Es indudable que la retracción del Estado en los últimos años ha contribuido a fortalecer esta imagen.

b) El rápido crecimiento del movimiento no sólo ha tenido repercusiones a nivel de las bases sino también de la estructura central de AIDESEP, cuyos dirigentes, muchos de ellos sin ninguna experiencia previa, se han visto confrontados a problemas muy serios que no han sabido cómo tratar. Tampoco han faltado algunos otros que han visto los cargos dirigenciales sólo como una posibilidad de acceso al poder y a ingresos fijos mensuales.

c) Complementando algo que ya dijimos en el punto anterior, debemos enfatizar que AIDESEP no tuvo una clara estrategia para formación de nuevos cuadros dirigenciales. Tampoco se intentó reformular los estatutos a fin de exigir calidades específicas y experiencia previa a quienes aspiraban a cargos nacionales. Esto dio como resultado que algunos comuneros que ni siquiera habían desempeñado funciones directivas en su comunidad o federación llegaran a ocupar puestos en la Oficina Nacional (ON) o, peor aun, que llegaran a ellos algunos que habían tenido un mal desempeño, tanto político como administrativo, en sus zonas.

d) AIDESEP no ha logrado readecuar su estructura organizativa inicial con la suficiente lucidez como para hacer frente a la situación actual, que es totalmente distinta. Como mencionamos, la organización surge sobre la base de cuatro federaciones, en un momento en que las decisiones políticas del país estaban totalmente centralizadas en Lima. Pocos años después, sin embargo, esta situación había cambiado muchísimo: las federaciones sobrepasaban las 
20 (hoy son cerca de 40) y el Perú se había comenzado a descentralizar. Si bien a partir de 1989 también AIDESEP comenzó a descentralizarse en las ORIs, este proceso, a nuestro entender, no ha sido suficientemente coherente. En 1991, por ejemplo, a pesar de la descentralización, los cargos nacionales aumentaron de 5 a 9 , cuando creemos que, por el contrario, debieron haberse reducido. Al mismo tiempo, no se diseñó la estructura, organización ni funciones de las ORIs, y cada una tomó a su cargo aquello que sus propias posibilidades le iban permitiendo. Hubo federaciones que enviaron proyectos ala ON, sin pasar por las ORIs para su opinión y consulta. Aprobados, fueron administrados directamente por la ON, con la pérdida de tiempo y de recursos que esto significa. Pero además este sistema impidió que las OR realicen un adecuado seguimiento del proyecto.

e) La relación de los dirigentes nacionales con las bases se debilitó. Al aumentar las federaciones, ya no fue posible realizar asambleas nacionales con la misma frecuencia, pasando éstas a constituir eventos que se hadan cada 3 años para cambio de dirigencia. Si bien algunos encuentros parciales de bases (de capacitación y otros) cubrieron en parte este vado, la deficiente definición del papel de las OR impidió la creación de mecanismos adecuados para estructurar mejor el movimiento.

f) Si bien creemos que fue positivo que AIDESEP declarase su autonomía respecto a partidos políticos y a los movimientos sociales que ellos lideraban, ya que esto le permitió acumular fuerzas y consolidar su propia posición, creemos que no debió haber mantenido la misma posición luego de haber alcanzado ese objetivo. Al hacerlo, se aisló socialmente al dejar de interesarse por problemas que no por ser de carácter general dejaban de afectar al movimiento indígena en su conjunto.

g) Lo que hemos dicho en el punto anterior, tiene que ver con una falsa imagen que muchos dirigentes han construido sobre los propios indígenas, en base a algo que queremos aquí calificar como "soberbia étnica". Opiniones como "somos indígenas y lo que pagan o piensen los blancos o mestizos es asunto de ellos” han sido frecuentes durante los años de vida de la organización. Esta forma equivocada de verse a sí mismos, ha llegado incluso a hacerse extensiva para considerar medidas que directa y específicamente afectaban al movimiento indígena, como la Constitución, la ley de tierras o el proyecto de ley forestal. 
h) El papel de los asesores (y ésta es además una autocrítica, ya que hemos desempeñado este papel dentro de la organización durante varios años), si bien es cierto le permitió al movimiento avanzar rápidamente, fue cubriendo demasiados vacíos que iban dejando sus dirigentes. En este sentido, su papel no siempre ha sido favorable para la maduración interna ni de los dirigentes ni del movimiento. Hubo un significativo avance en el discurso teórico, pero éste se apartó de las condiciones reales en que se encontraban las bases e incluso muchos dirigentes nacionales. $\mathrm{Al}$ mismo tiempo, consideramos que la relación entre dirigentes y asesores no ha sido sana ni equilibrada: a pesar de que éstos cubrían sus vacíos y, muchas veces, maquillaban sus equívocos, eran acusados por los primeros de las fallas y errores del movimiento, liberándose así de su propia responsabilidad.

i) Los conflictos interétnicos, que en un momento se pensó que habían sido superados por la bandera de la solidaridad indígena, han jugado también un papel importante en la crisis. Estos han tenido repercusión no sólo a nivel interno de la dirigencia nacional (entre aguarunas, shipibos y ashánincas), sino también de las mismas federaciones regionales. Los conflictos tradicionales entre pueblos vecinos, como los Aguaruna y los Huambisa, siempre han estado latentes y han vuelto a tomar vigencia frente al cuestionamiento del actual presidente del CAH. En el Alto Mayo, las pugnas entre aguarunas nativos de la zona y los llegados de otras cuencas determinaron, junto a otros factores, el rompimiento de la organización.

j) El caudillismo de muchos dirigentes ha sido también factor determinante en la crisis, ya que éste ha impedido desarrollar una concepción política clara sobre la organización como un movimiento que se gesta dentro de un proceso de largo plazo. Al igual que lo que sucede a nivel nacional, varias veces se ha presentado el caso que un nuevo presidente de AIDESEP se dedique a criticar lo que había hecho su predecesor, quien, por su lado, desde su nueva ubicación, trataba de minar lo que ése hacía o pensaba realizar. El manejo institucional ha sido personalista y así lo han percibido las propias bases, quienes consideraban que recibían apoyo de una persona y no de una organización.

k) Las propuestas programáticas del movimiento sufrieron un debilitamiento como consecuencia de muchas de las causas de la crisis antes expuestas (caudillismo, conflictos, aislamiento, crecimiento vertiginoso, etc.), pero 
también de la facilidad que tuvo AIDESEP para acceder a fondos internacionales. En este sentido, planteamos también una crítica al papel desarrollado por las agencias de cooperación, muchas de las cuales, con muy poca información respecto a la utilidad y viabilidad del proyecto, le proporcionaron fondos, a veces en cantidades excesivas, que sirvieron más para generar problemas internos que para apoya su consolidación. Consideramos también que los mecanismos de esas agencias para dar seguimiento y realizar el control administrativo y contable han sido deficientes.

1) Finalmente, queremos también mencionar una razón de carácter geográfica que ha contribuido a la falta de estructuración interna del movimiento: las dificultades de comunicación y lo extenso de las áreas de dispersión dentro de las cuales se encuentran las comunidades bases de muchas federaciones.

En meses pasados, una nueva dirigencia ha asumido la conducción de AIDESEP. Se trata de un grupo de líderes que ha reflexionado críticamente sobre la evolución del movimiento en los últimos años y que declara querer trabajar para cambiar la actual situación.

La crisis del movimiento ha generado también una crisis en las agencias de cooperación y en los profesionales que han actuado como asesores. Tanto ésas como éstos afirman la necesidad de revisar su propio trabajo.

En necesario esperar un tiempo para ver si la reflexión de todos esos actores madura a través de propuestas que puedan devolverle al movimiento indígena la vitalidad que tuvo en sus inicios.

\section{Referencias}

AIDESEP. Esclavitud indígena en la región de Atalaya. Amazonía Indígena, Lima, año 11, n. 17-18, p. 3-14, 1991a.

AIDESEP. Aprovecha mi poco conocimiento de las leyes. Amazonía Indígena, Lima, año 11, n. 17-18, p. 14-16, 1991 b.

AIDESEP. Nos dicen que somos indígenas y si nos matan nada pasa. Amazonía Indígena, Lima, año 11, n. 17-18, p. 16-21, 1991c. 
CASANTO, R. 25 años de experiencias organizativas en la sociedad Asháninka del Perú. In: GASCHÉ, J.; ARROYO, J. M. (Comp.). Balances amazónicos. Iquitos: CIAAP: CNRS: MAB, 1986. p. 225-237.

CONAP. Deslinde con AIDESEP. La autodeterminación es un pretexto para la división. Boletín CONAP, año 3, n. 4, 1990.

CHIRIF, A. Comentario al artículo "El retorno del indio" de Xavier Albó. Revista Andina, año 9, n. 2, p. 253 257, 1991. 